\section{A Case of Primary Undifferenti- ated Pleomorphic Sarcoma of the Lung}

Sir,

Undifferentiated sarcomas comprise upto $20 \%$ of all sarcomas. Malignant fibrous histiocytoma (MFH) and its subtypes have been finally removed from the WHO 2013 classification. ${ }^{1,2}$ Many tumors previously classified as MFH have been reclassified as "undifferentiated pleomorphic sarcomas" (UPSs). ${ }^{3}$ UPS is extremely rare among the primary tumors of the lung $(<0.5 \%$ of all lung cancers) and is essentially a diagnosis of exclusion. Primary UPS of the lung was previously reported in approximately 85 cases in literature. ${ }^{4}$ Two-hundred cases of soft tissue MFH were presented first by Weiss and Enzinger in 1978. ${ }^{5}$ After one year, Bedrossian et al. described the first case of primary pulmonary MFH. ${ }^{6}$

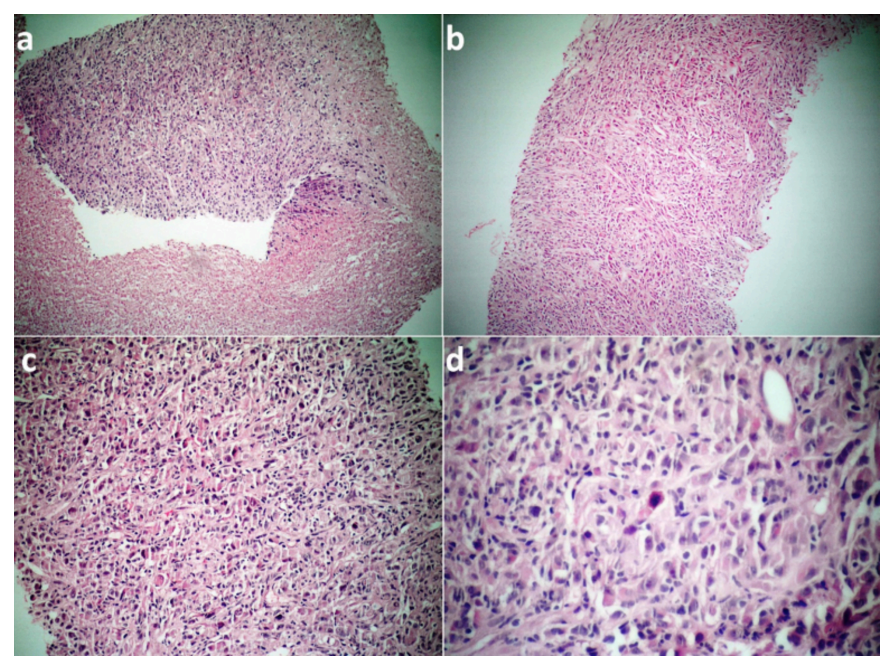

Figure 1: (a) Low-power microphotograph of the biopsy showing a large area of necrosis adjacent to undifferentiated malignant tumor (H\&E, $\times 100)$. (b) Another low-power microphotograph showing undifferentiated pleomorphic sarcoma with pleomorphic spindle-shaped cells arranged in a vague storiform pattern (H\&E, $\times 100)$. (c) Pleomorphism is prominent in this focus. The tumor is composed of plump fibroblastic cells and histiocyte-like cells arranged haphazardly in sheets. $(H \& E, \times 200)(d)$ Chronic inflammatory cells and a mitotic figure are also seen (H\&E, X400).

A 52-year-old female patient presented to the chest diseases clinic for cough and shortness of breath. Her medical history was unremarkable except for cholecystectomy operation. She had no history of asbestos exposure. Chest X-ray and computed tomography (CT) revealed a mass lesion with cystic component with a diameter of $10 \mathrm{~cm}$ in the right lung base, with irregular thickening of the pleura. CT-guided tru-cut biopsy was performed from the wall of the cystic mass. Microscopic examination showed tumoral infiltration with high grade cytological features and large necrotic areas (Figure 1a). The tumor showed a combination of pleomorphic and storiform areas (Figure 1b, 1c). Pleomorphic areas were more prominent and consisted of fibroblastic cells and histiocyte-like cells arranged haphazardly in sheets. The nuclei were hyperchromatic, pleomorphic, with prominent nucleoli (Figure 1c). Chronic inflammatory cells and numerous mitotic figures were also seen (Figure 1d). Immunohistochemically, the tumor cells were diffusely positive for vimentin and CD68, and were focally weakly positive for S-100 and EMA (Figure 2a, 2b). However, the tumor was negative for pan-CK, TTF-1, CK5/6, Calretinin, Desmin, CEA and CD34 (Figures 2c, 2d). The patient was diagnosed with the UPS, based on morphological and immunohistochemical findings. Any possible extrapulmonary origin was ruled out by clinical examination.

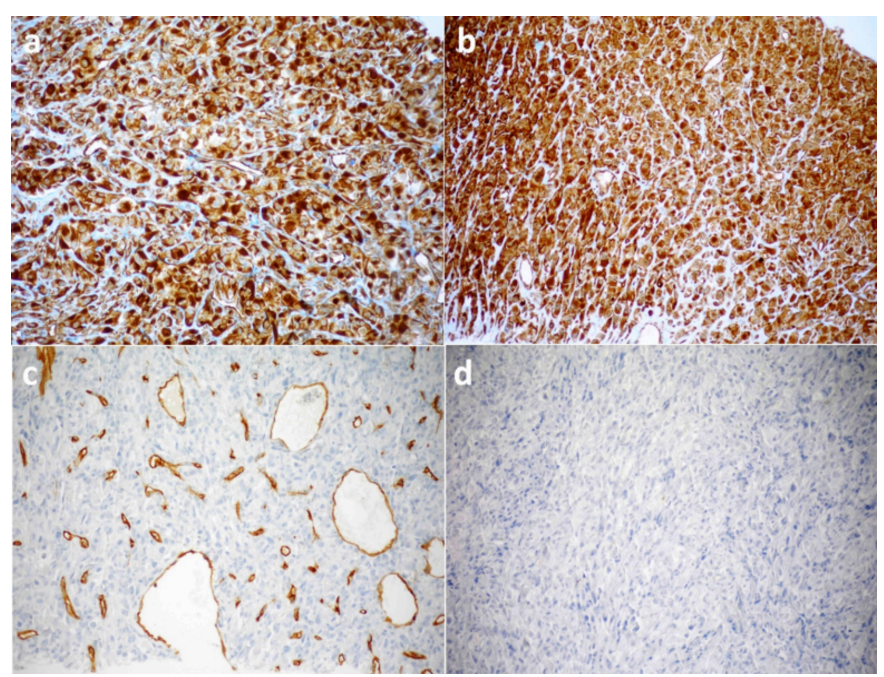

Figure 2: Immunostaining findings. (a) Vimentin was positive $(\times 200)$. (b) Immunostaining for CD68 was positive $(\times 200)$. (c) The tumor was negative for CD34 ( $\times 200)$. (d) The tumorwas negative for pan-CK $(\times 200)$.

The case was considered inoperable because of deterioration in the patient's general condition, the aggressive character of the tumor, and presence of criteria for poor prognosis. She received two cycles of chemotherapy and died four months after the diagnosis.

The pleural and peripheral pulmonary parenchymal localisation, solitary solid-cum-cystic mass form, and nonspecific clinic-radiological properties are the general characteristics of the tumor. However, the most important parameter that differentiates UPS from the epithelial tumors of the lung and the tumors with sarcomatoid features is the morphological and immunohistochemical findings in the microscopic examination. Molecular studies can be helpful to rule out other tumors that display similar histological findings. ${ }^{4}$ It is necessary to exclude other malignant neoplasms that can resemble UPS, including other types of sarcomas, sarcomatoid carcinomas, malignant melanoma, or sarcomatoid mesothelioma. ${ }^{4}$ The management approach to the tumor is variable, and the primary treatment is complete resection, if possible. ${ }^{4}$ The role of chemotherapy and radiotherapy on survival are indeterminate. The tumor size and histologic grade are important in determining the prognosis. 


\section{PATIENT'S CONSENT:}

Informed consent was obtained from the patient.

\section{CONFLICT OF INTEREST:}

The authors declared no conflict of interest.

\section{AUTHORS' CONTRIBUTION:}

AK: Writing-original draft, final approval, analysis and interpretation of data.

FY: Literature review, designing.

HK: Data collection, editing, critical review.

$\mathrm{NU}$ : Designing, analysis.

\section{REFERENCES}

1. Jo VY, Fletcher CD. WHO classification of soft tissue tumours: An update based on the 2013 (4th) edition. Pathology 2014; 46(2):95-104. dol: 10.1097/ PAT.0000000000000050.

2. Vilanova JC. WHO classification of soft tissue tumors. In: Vanhoenacker FM, Filip M, Parizel PM, Gielen JL. Eds. Imaging of soft tissue tumors ed. 4th, Cham; Springer; 2017: p.187-96.

3. Fletcher CDM, Bridge JA, Hogendoorn PCW, Mertens F. WHO classification of tumours of soft tissue and bone. ed. 4th, Lyon: IARC Press; 2013.

4. Qorbani A, Nelson SD. Primary pulmonary undifferentiated pleomorphic sarcoma (PPUPS). Autopsy Case Rep 2019; 9(3):e2019110. dol:10.4322/acr.2019.110.
5. Weiss SW, Enzinger FM. Malignant fibrous histiocytoma: An analysis of 200 cases. Cancer 1978; 41(6):2250-66. doI:10.1002/1097-0142(197806)41:6<2250::AIDCNCR2820410626>3.0.CO;2-W.

6. Bedrossian CW, Verani R, Unger KM, Salman J. Pulmonary malignant fibrous histiocytoma: Light and electron microscopic studies of one case. Chest 1979; 75(2):186-9. dol: $10.1378 /$ chest.75.2.186.

Asuman Kilitci ${ }^{1}$, Fahri Yilmaz', Haciali Kilicgun ${ }^{3}$ and Nesrin Uygun ${ }^{4}$

${ }^{1}$ Department of Pathology, Faculty of Medicine, Kirsehir Ahi Evran University, Kirsehir, Turkey

${ }^{2}$ Department of Pathology, Faculty of Medicine, Sakarya University, Sakarya, Turkey

${ }^{3}$ Department of Thoracic Surgery, Faculty of Medicine, Abant Izzet Baysal University, Bolu, Turkey

${ }^{4}$ Department of Pathology, Faculty of Medicine, Istanbul University Cerrahpasa, Istanbul, Turkey

Correspondence to: Dr. Asuman Kilitci, Department of Pathology, Faculty of Medicine, Kirsehir Ahi Evran University Kirsehir, Turkey

E-mail: dr.asuk@gmail.com

Received: September 04, 2020; Revised: October 13, 2020; Accepted: November 07, 2020

DOI: https://doi.org/10.29271/jcpsp.2021.11.1380 